\title{
Differential development of 24 -h retention capacities for two components of T-maze escape learning by infant mice
}

\author{
Z. MICHAEL NAGY, MARC R. PAGANO, and DENISE GABLE \\ Bowling Green State University, Bowling Green, Ohio, 43403
}

\begin{abstract}
At 9 or 11 days of age, separate groups of Swiss-Webster mice received 12, 24, or 40 training trials to the goal opposite their first-trial choice in a shock-escape T-maze task. All groups were retested to the same goal for 25 trials $24 \mathrm{~h}$ following training, while maturation controls without prior exposure were trained to the goal opposite their first choice. All groups demonstrated increased escape proficiency during original training on two separate escape components: reaching the choice point and making the correct turn at the choice point. During retention testing, all groups at both ages exhibited better escape performance in terms of reaching the choice point than their maturation controls. However, when escape was measured in terms of choice, none of the groups trained at 9 days of age differed significantly from maturation controls when retested at 10 days of age. In contrast, retention of correct choice point turn varied directly with number of original training trials for mice trained at 11 days of age.
\end{abstract}

An increasingly large number of studies investigating the ontogeny of memory have reported large differences in retention as a function of age at original training, and it is now well established that long-term retention of learned tasks, particularly those involving aversive stimuli, is much poorer in young animals than in adults (cf. Campbell, Riccio, \& Rohrbaugh, 1971; Campbell \& Spear, 1972). As the primary interest in such studies has been differences in retention as a function of age, the youngest age groups have necessarily been old enough to demonstrate levels of acquisition which were comparable, or nearly so, to adults', and the youngest age groups used have typically been 20-25 days of age, although several reports have used younger subjects. Presumably, disparate retest scores of the different age groups are reflecting differences in retention capacities rather than learning capacities, and subsequent research (e.g., Campbell, Misanin, White, \& Lytle, 1974) has suggested that neurological maturity at the time of original learning is a major determinant of long-term memory.

More recent investigations have attempted to determine the developmental stages at which learning abilities and retention capacities on different instrumental tasks first become behaviorally evident. On a simple straightalley shock-escape task, both mice and rats as young as 5 days of age have been reported to demonstrate improved escape responding during acquisition trials. However, retention of this improved performance is very poor, being less than $6 \mathrm{~h}$ until the mice and rats are 9 days of age, at which time retention capacity improved to at least $24 \mathrm{hr}$ for the rat (Misanin, Nagy, Keiser, \& Bowen, 1971) and $96 \mathrm{~h}$ for the mouse (Nagy, Misanin, Newman, Olsen, \& Hinderliter, 1972). On a

This research was supported in part by National Science Foundation Research Grant GB-30456. Reprints may be obtained from the first author, Department of Psychology, Bowling Green State University, Bowling Green, Ohio 43403. more complex discriminated shockescape T-maze, both rats and mice are capable of demonstrating improved performance within a 25-trial training session by 9 days of age (Misanin, Haigh, Hinderliter, \& Nagy, 1973; Nagy \& Sandmann, 1973). However, 24-h retention capability of prior T-maze training for the mouse is not evident until 11 days of age (Nagy \& Murphy, 1974; Nagy \& Sandmann, 1973); retention capabilities at that age for the rat have not yet been reported.

While it is tempting to attribute the emergence of these apparent learning and retention abilities on these escape tasks to some aspect of the numerous maturational changes in brain function which are known to be occurring at these ages at about comparable ages in both mouse and rat (cf. Himwich, 1970), it must first be clearly established that the failure to find evidence of learning or retention of these tasks at certain ages is due to the undeveloped capacity at that age rather than to parameters of the training and retention test procedures utilized. In the previous studies with infant mice, training and retention tests consisted of 25 escape trials in the T-maze. While both 9- and 11-day old mice demonstrated improved escape performance during training, only the 11-day-old mice exhibited evidence of retention for the trained goal when retested $24 \mathrm{~h}$ later. However, as the 9-day-old groups also showed lower levels of acquisition by the end of training than did 11-day-olds, it is possible that additional training at 9 days of age would have resulted in 24-h retention of the correct choice-point turn.

The primary purpose of the present investigation was to examine the 24-h retention of mice trained on a T-maze escape task at 9 and 11 days of age as a function of the number of original training trials. A secondary purpose was to determine whether separable components of the escape response might also be retained differentially as a function of age and number of original training trials. Kukleta (1968) has reported evidence 


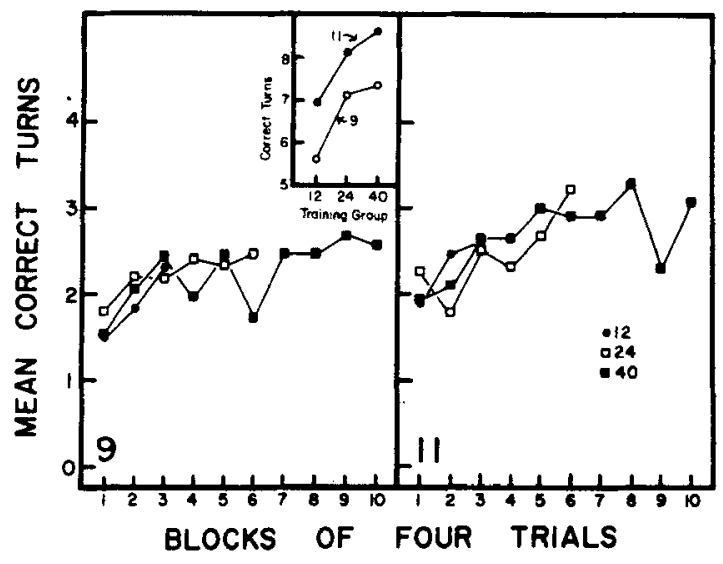

Figure 1. Mean number of correct choice point turns as a function of age, training groups, and trial blocks. Figure inset depicts the mean number of correct turns made over the last three trial blocks for each training group as a function of age.

with adult rats that the shock-escape reaction consists of two components, each with its own memory system. One component is related to the locomotor movements required to escape (form of response), and the second involves the ability to localize the goal. In the T-maze situation, the form of the response might be reflected by the subject learning to run directly to the choice point without competing responses, while the goal location component would be reflected by goal direction upon reaching the choice point. Nagy and Murphy (1974) have provided data suggesting that these two escape components are separable during T-maze learning in infant mice; however, differential retention of the two components could not be clearly concluded from the experimental design employed.

\section{METHOD}

\section{Subjects}

The subjects were 144 Swiss-Webster male and female mice (Mus musculus) born and reared in polyethylene cages with wiregrid tops and wood chips on the floor. The mice were tested between 9-12 days of age, and remained with the mothers and littermates at all times except during training sessions. Ad lib food and water were provided, and the colony and test rooms were maintained at $24 \pm 1^{\circ} \mathrm{C}$.

\section{Apparatus}

The apparatus was a Plexiglas T-maze, $6.2 \mathrm{~cm}$ high and $3.4 \mathrm{~cm}$ wide throughout. The stem was $18.8 \mathrm{~cm}$ long, with a removable door placed $5 \mathrm{~cm}$ from the closed end to form the startbox. Each arm of the maze was $9.2 \mathrm{~cm}$ long. The maze was placed upon a grid floor, composed of $1-\mathrm{mm}$ stainless steel rods spaced $3 \mathrm{~mm}$ center-to-center, such that the grids were parallel to the maze stem and perpendicular to the length of the arms. A scrambled AC shock source (Harvard Instrument Co., Model 3121) delivered .1 mA constant current to the grid floor.

\section{Procedure}

At 9 or 11 days of age, separate groups of 9 males and 9 females were assigned to 1 of 4 training groups according to a split-litter design. One of the groups ( 0 group) at each age served as a maturation control and was simply removed from the nest, toe-clipped for identification, and then returned to the home cage at the appropriate training age. For the remaining groups, a training trial was begun by placing the mouse in the startbox, facing the choice point, with the door in place. After $5 \mathrm{sec}$, the door was removed, shock initiated, and a running time meter started. The 1 st trial was used to determine turn preference, and all mice received shock offset for reaching within $6 \mathrm{~mm}$ of the end of either goal arm. On subsequent trials, the trained groups at each age received 12,24, or 40 trials on which shock offset occurred for reaching the end of the goal arm which was opposite each mouse's initial trial preference. If a mouse failed to reach the correct goal within $300 \mathrm{sec}$, it was gently prodded to the correct goal, shock was terminated, and a maximum latency score of $300 \mathrm{sec}$ was assigned. A 45-sec intertrial interval was used, during which time the mouse was held in the experimenter's closed hand. Following training, the mice were toe-clipped for identification and returned to the home cage.

Twenty-four hours following original training, all previously trained mice received an additional 25 training trials to the goal to which they had been originally trained. The maturation control groups also received 25 training trials at this time, with the 1 st trial being used to establish turn preference. The following 24 trials were to the goal opposite the 1st trial choice for each mouse in the respective control groups.

Two performance measures were recorded during the training and retest sessions. The first was the goal arm entered (one-half body length) upon first reaching the choice point during each trial. The second measure was the number of competing responses made prior to reaching the choice point on each trial. Competing responses were defined as $180-\mathrm{deg}$ turns made in the stem away from the direction of the choice point. A decrease in competing responses was considered to reflect improvement in the form component of the escape response (Nagy \& Murphy, 1974).

\section{RESULTS}

\section{Original Training}

As the first trial was used to determine turn preference, first trial scores for all groups on both measures were excluded from the analyses. The remaining scores were totaled for each block of four trials, with each measure being separately analyzed by a series of factorial analyses of variance with one repeated measure (Winer, 1971). In order to determine whether groups ending training after a certain number of trials were comparable to those groups receiving further training, separate analyses of variance were conducted over the first 3,6 , and 10 trial blocks of appropriate groups. In addition, an analysis of variance was conducted on each performance measure over the last three trial blocks for each group to determine relative differences in performance during the later portions of training. Except for the analyses over 10 trial blocks which involved only 1 training group (40), the factors in each analysis of variance were age, training group, sex, and trial blocks. Sex proved not to be reliable either as a main effect or as an interaction in any of the analyses for either performance measure, and these groups have been combined for all comparisons.

Correct Choice Point Turns. Figure 1 presents the mean number of correct choice point turns as a function 
of age, training groups, and trial blocks. As suggested by the figure, all training groups at both ages demonstrated reliable increases in the number of correct turns made over trial blocks (all ps $<.005$ ) and, in each comparison, 11-day-old mice made more correct turns over a particular number of training trials than did 9-day-old mice (all ps $<.025$ ). In addition to the overall age effect, the data also suggest differential rates of improvement for the two age groups. The 9-day-old mice appeared to reach asymptotic performance after 12 trials, evidencing only slight improvement with additional training. In contrast, the 11-day-old mice continued to increase the number of correct turns over the first 24 trials. These differential rates of improvement resulted in significant Age by Trial Block interactions over $24[\mathrm{~F}(5 / 320)=2.81 ; \mathrm{p}<.025]$ and 40 $[F(9 / 288)=2.04 ; p<.05]$ trials. Within each of the ages, performance of the training groups was comparable over the first 12 and 24 trials.

The figure inset depicts the mean number of correct turns made over the last three trial blocks for each of the training groups as a function of age. Overall, the analysis indicated an increase in correct turns as a function of the number of training trials $[F(2 / 96)=$ $10.22 ; \mathrm{p}<.0005]$ and age $[\mathrm{F}(1 / 96)=10.01 ; \mathrm{p}<.005]$. Duncan's multiple-range tests indicated that both age groups receiving 12 training trials made fewer correct turns over the last 3 trial blocks than did those groups receiving 24 or 40 training trials (both ps $<.05$ ); the 24and 40-trial groups did not reliably differ from one another at either age.

Competing Responses. The mean number of competing responses made before the choice point is presented in Figure 2 as a function of age, training groups, and trial blocks. While the 11-day-old groups made fewer competing responses than did 9-day-olds (all ps $<.0005$ ) all training groups at both ages displayed a decrease in competing responses over their respective numbers of

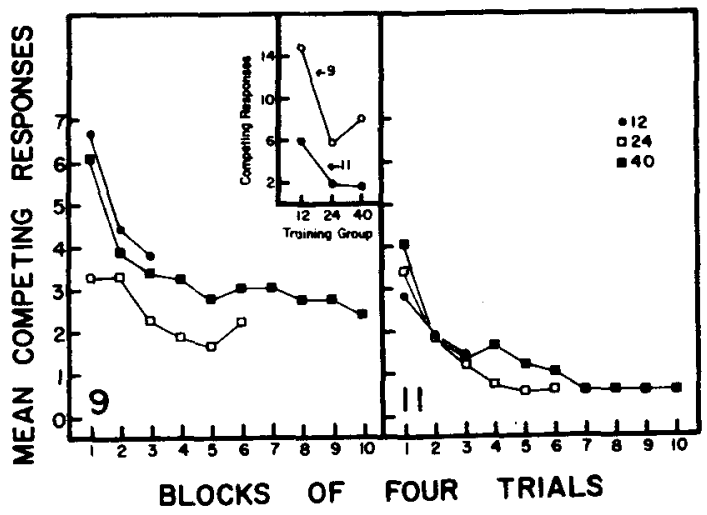

Figure 2. Mean number of competing responses made before the choice point as a function of age, training groups, and trial blocks. Figure inset shows mean number of competing responses made during the last three trial blocks for each of the training groups as a function of age.

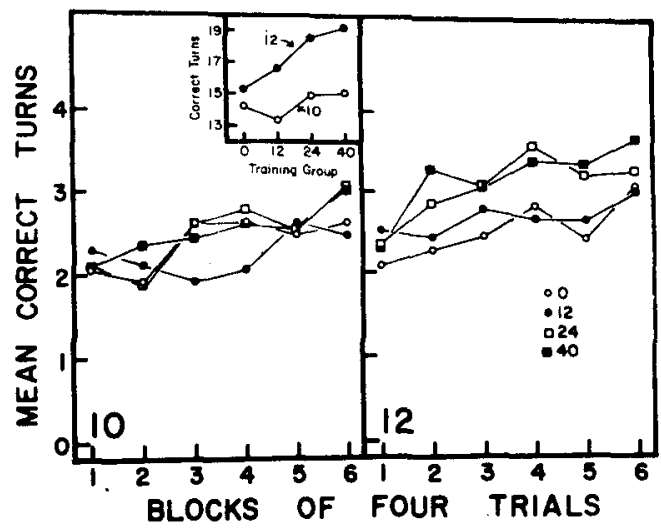

Figure 3. Mean number of correct choice point turns during retention as a function of age, training groups, and trial blocks. Figure inset presents mean number of total correct turns as a function of age and amounts of original training.

training trials (all ps $<.0005$ ), suggesting increasing proficiency in reaching the choice point. With the exception of the 9-day-old 24-trial group, performance within ages was equivalent between training groups over comparable training trials. Although the 9-day-old 24-trial groups made fewer competing responses over comparable training trials than the 12 - and 40-trial groups, this difference would appear to reflect sampling error rather than differences in learning capacity, especially since it was relatively consistent over training trials. However, this disparity resulted in an Age by Training Group interaction $[\mathrm{F}(2 / 96)=4.58 ; \mathrm{p}<.05]$ over the first three trial blocks.

The figure inset displays the mean number of conipeting responses made over the last 3 trial blocks by each of the training groups. The analysis of variance indicated reliable main effects for age $[\mathrm{F}(1 / 96)=87.03$; $\mathrm{p}<.0005]$ and training group $[\mathrm{F}(2 / 96)=37.82$; $\mathrm{p}<.0005]$; the interaction between age and training group $[F(2 / 96)=4.33 ; \mathrm{p}<.025]$ was significant. Individual comparisons conducted within the Age by Training Group interaction demonstrated that both age groups receiving 24 and 40 trials made fewer competing responses over their last 12 trials than did comparable age groups receiving only 12 trials $[\operatorname{Fs}(1 / 96)=6.60$; ps $<.025]$; the 24-trial and 40-trial groups within each age were not significantly different $[\mathrm{Fs}(1.96)$ $<1.75$ ].

In summary, the training data indicate that although 11 -day-old groups performed consistently better on both performance measures than did 9-day-old groups, all training groups displayed improved escape performance over trial blocks as measured by significantly increasing numbers of correct choice point turns and decreasing numbers of competing responses prior to reaching the choice point. Comparisons of scores over the last 12 trials for all groups suggest that both 9- and 11-day-old groups approach or reach asymptotic levels of performance within the first 24 training trials, with little 


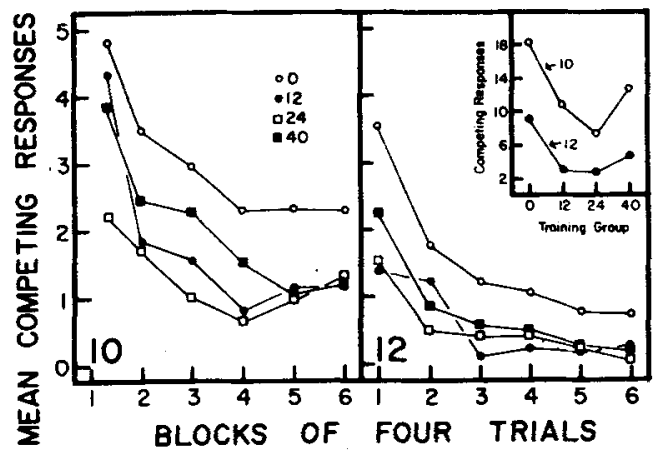

Figure 4. Mean number of competing responses made before the choice point during retention testing as a function of age, training groups, and trial blocks. Figure inset depicts mean number of total competing responses as a function of age and amounts of original training.

improvement being indicated by either escape measure with further training.

\section{Retention}

Data from the first retest trial of the previously trained groups and the preference trial of the maturation control groups were excluded from the analyses. Each performance measure during retest was submitted to a factorial analysis of variance with one repeated measure. The factors were age, training group, sex, and trial blocks. Once again, sex proved to be insignificant as a main effect or interaction for either performance measure, and these groups have been combined for all comparisons.

Correct Choice Point Turns. The mean number of correct choice point turns during retention is presented in Figure 3 as a function of age, training group, and trial blocks. Reliable main effects were found for age $[F(1 / 128)=42.97 ; \mathrm{p}<.0005]$, training group $[\mathrm{F}(3 / 128)=7.37 ; \mathrm{p}<.0005]$, and trial blocks $[F(5 / 640)=15.78 ; p<.0005]$. Although the Age by Training Group interaction failed to reach significance $[\mathrm{F}(3 / 128)=2.15 ; \mathrm{p}<.10]$, planned comparisons were conducted within this interaction by means of $t$ tests. As suggested by the figure inset, all 9-day-old training groups failed to differ reliably from one another [all ts $(34)<1.98$; all ps $>.05$ ], indicating that a prior training session of up to 40 trials did not result in reliable retention effects at 10 days of age. In contrast, groups with 24 and 40 prior training trials at 11 days of age made significantly more correct choice-point turns upon retest than groups with either 12 or 0 trials [ts $(34)>2.24$; ps $<.05$ ]. All 12-day-old groups with prior training made more correct turns than did 10-dayold groups with comparable amounts of training [all ts (34) $>3.78$; ps $<.001$ ], while the 10- and 12-day-old maturation control groups without prior training failed to differ significantly [t $(34)=1.06]$.

Competing Responses. Figure 4 presents the mean number of competing responses made prior to reaching the choice point during retention testing as a function of age, training group, and trial blocks. Overall, 12-day-old mice made fewer competing responses than did 10-dayold groups $(\mathrm{p}<.0005)$ and competing responses decreased over trial blocks $(\mathrm{p}<.0005)$. The significant effect of training group $[F(3 / 128)=15.60 ; p<.0005]$ was further examined by $t$ test comparisons of training groups within ages. As suggested by the figure inset, groups with prior training at both ages made fewer competing repoonses than did their respective maturation control groups with no prior training [all ts (34) $>2.13$; ps $<.05]$. With one exception, within-age comparisons between groups with prior training were not significant [all ts $(34)<1.89$ ]. The exception was the 10-day-old 24-trial group which made fewer competing responses than the 40-trial group $[\mathrm{t}(34)=2.50$; $\mathrm{p}<.02]$. While it may appear odd that a group which had fewer original training trials would exhibit better retest performance on this measure than a group which had a greater amount of original training, it must be recalled that the 24-trial group also made fewer competing responses than the other 9-day-old groups during original training. Thus, the relatively low number of competing responses made by the 24-trial group during retest appears due to some inherent factor of that particular group of subjects rather than to an unexpected relationship between amount of original training and retest performance. In general, these retest data suggest that within ages, groups receiving $12-40$ original training trials exhibit equivalent retest performance in reaching the choice point, and all do so more efficiently than groups without prior training.

\section{DISCUSSION}

A finding of age-related differences in the retention of prior training may be due either to differences in the strength of original learning between the age groups or to ontogenetic differences in the storage and/or retrieval mechanisms of retention (Campbell \& Spear, 1972). The fact that 11-day-old mice exhibited superior escape performance in comparison to 9-day-old mice on both escape components over comparable numbers of original training trials, therefore, makes direct comparisons of retention scores between age groups somewhat tenuous. However, within-age comparisons of retention scores strongly suggest that the age-related retention differenc. es are due in large part to ontogenetic differences in the storage and/or retrieval mechanisms of retention. Mice receiving up to 40 original training trials at 9 days of age failed to make more correct choice point turns than nontrained controls when retested at 10 days of age. In contrast, littermates trained at 11 days of age exhibited 24-h retention scores which varied directly as a function of the number of original training trials. Since both age groups demonstrated general increases of correct turns during original training as a function of the 
number of original training trials, the failure to find evidence of 24-h retention differences at 10 days of age would suggest that those mechanisms underlying 24-h retention of goal location for this task are not yet functional at 9 days of age, whereas they are by 11 days of age. At the very least, it can be stated that 40 training trials are not sufficient to result in 24-h retention of goal location on this task at 9 days of age.

The competing response data are in good agreement with those reported by Nagy and Mueller (1973), which demonstrated that 9-day-old mice receiving 1040 original training trials in a straight-alley escape task showed reliable $24-\mathrm{h}$ retention of inhibition of the competing response. In contrast, 7-day-old mice receiving comparable amounts of training failed to differ from nontrained controls when tested at 8 days of age. In the present study, mice receiving $12-40$ original training trials at 9 and 11 days of age made fewer competing responses upon retest than their respective nontrained control groups, suggesting retention of that escape component for all groups with prior training. While these findings support the hypothesis that 24-h retention capacities for different components of the T-maze escape task become functionally mature at different stages of ontogeny, whether or not separate memory systems exist for the two escape components is unclear. Although the present data could be interpreted as reflecting separate memory systems, they may also reflect the development of a single memory system which retains or retrieves increasingly complex kinds of information as maturation proceeds.

In general, the results of this investigation are in accord with the notion that learning and retention capacities will behaviorally emerge during ontogeny with the functional maturation of physiological processes underlying these capacities. Presumably, more complex responses or tasks will require further central nervous system maturation than less complex tasks and should emerge during a later stage of ontogeny. If the goal location component of the T-maze escape task is regarded as being more complex than the form component, then it might be expected that the learning and retention capacities for that component would develop at a later age as indicated in the present data.

While the presence of a 24-h retention capacity for the goal location cannot be completely ruled out by the present data for mice 9 days of age, the present study would suggest that the failure to detect that capacity is not due to insufficient original training. It has recently been demonstrated (Nagy, 1975) that variation of drive (shock) level does not result in earlier onset of goal location retention on this task. Nine-day-old mice failed to evidence 24-ih retention of goal location after receiving 25 training trials at either .1 or $.2 \mathrm{~mA} ; 11$-day-old mice showed reliable retention of goal location independent of drive level during either training or retest. Whether the variation of other training parameters will result in 24-h retention of goal location by 9-day-old mice remains to be demonstrated.

\section{REFERENCES}

Campbell, B. A., Misanin, J. R., White, B. C., \& Lytle, L. D. Species differences in ontogeny of memory: Indirect support for neural maturation as a determinant of forgetting. Journal of Comparative and Physiological Psychology, 1974, 87, 193-202.

Campbell, B. A., Riccio, D. C., \& Rohrbaugh, M. Ontogenesis of learning and memory: Research and theory. In $M$. $E$. Meyer (Ed.). Second Western Washington symposium on learning: Early learning. Bellingham: Western Washington State College Press, 1971. Pp. 76-109.

Campbell, B. A., \& Spear, N. E. Ontogeny of memory. Psychological Review, $1972,79,215-236$.

Himwich, W. A. Developmental neurobiology. Springfield Thomas, 1970 .

Kukleta, M. Memory components of shock escape reaction in rat. Physiology and Behavior, $1968,3,773-776$.

Misanin, J. R., Haigh, J. M., Hinderliter, C. F., \& Nagy, Z. M. Analysis of response competition in discriminated and nondiscriminated escape training of neonatal rats. Journal of Comparative and Physiological Psychology, 1973, 85, 570-580.

Misanin, J. R., Nagy, Z. M. Keiser, E. F., \& Bowen, W. Emergence of long-term memory in the neonatal rat. Journal of Comparative and Physiological Psychology, 1971. 77, 188-199.

$\mathrm{Nagy}, \mathrm{Z}$. M. Effect of drive level upon age of onset of 24-h retention of discriminated escape learning in infant mice. Bulletin of the Psychonomic Society, 1975, 6, 22-24.

Nagy, Z. M., Misanin, J. R. Newman, J. A., Olsen, P. L., \& Hinderliter, C. F. Ontogeny of memory in the neonatal mouse. Journal of Comparative and Physiological Psychology, 1972, 81, 380-393.

Nagy, Z. M., \& Mueller, P. W. Effect of amount of original training upon onset of a 24-hour memory capacity in neonatal mice. Journal of Comparative and Physiological Psychology, 1973, 85, 151-159.

Nagy, Z. M., \& Murphy, J. M. Learning and retention of a discriminated escape response in infant mice. Developmental Psychobiology, 1974, 7, 185-192.

Nagy, Z. M.. \& Sandmann, M. Development of learning and memory of $T$-maze training in neonatal mice. Journal of Comparative and Physiological Psychology, 1973, 83, 19-26.

Winer, B. J. Statistical principles in experimental design. (2nd ed.) New York: McGraw-Hill, 1971.

(Received for publication April 28, 1975.

Revision accepted September 22, 1975.) 